\title{
Postheated Model of Confined High Strength Fibrous Concrete
}

\author{
Kaleem A. Zaidi, ${ }^{1}$ Umesh K. Sharma, ${ }^{2}$ N. M. Bhandari, ${ }^{2}$ and P. Bhargava ${ }^{2}$ \\ ${ }^{1}$ Civil Engineering Section, Aligarh Muslim University, Aligarh, India \\ ${ }^{2}$ Department of Civil Engineering, Indian Institute of Technology, Roorkee, India
}

Correspondence should be addressed to Kaleem A. Zaidi; kaleemzaidi@rediffmail.com

Received 16 June 2016; Accepted 25 October 2016

Academic Editor: Lucio Nobile

Copyright (c) 2016 Kaleem A. Zaidi et al. This is an open access article distributed under the Creative Commons Attribution License, which permits unrestricted use, distribution, and reproduction in any medium, provided the original work is properly cited.

\begin{abstract}
HSC normally suffers from low stiffness and poor strain capacity after exposure to high temperature. High strength confined fibrous concrete (HSCFC) is being used in industrial structures and other high rise buildings that may be subjected to high temperature during operation or in case of an accidental fire. The proper understanding of the effect of elevated temperature on the stress-strain relationship of HSCFC is necessary for the assessment of structural safety. Further stress-strain model of HSCFC after exposure to high temperature is scarce in literature. Experimental results are used to generate the complete stress-strain curves of HSCFC after exposure to high temperature in compression. The variation in concrete mixes was achieved by varying the types of fibre, volume fraction of fibres, and temperature of exposure from ambient to $800^{\circ} \mathrm{C}$. The degree of confinement was kept constant in all the specimens. A comparative assessment of different models on the high strength confined concrete was also conducted at different temperature for the accuracy of proposed model. The proposed empirical stress-strain equations are suitable for both high strength confined concrete and HSCFC after exposure to high temperature in compression. The predictions were found to be in good agreement and well fit with experimental results.
\end{abstract}

\section{Introduction}

It is well known that the higher load carrying capacity of high strength concrete is normally accompanied by more brittle behaviour; however, this property can be compensated in a rational manner through incorporating the confinements by lateral reinforcement with and without fibres [1-6]. The concept of using a combination of suitable randomly distributed discrete fibres with nominal amount of lateral steel has been discussed in the literature to ease the requirement of high amount of confinement in the plastic hinge regions of high strength concrete columns [7,8]. Fibre reinforced high strength confined concrete is becoming very popular in recent decades due to the excellent earthquake resisting characteristics such as high ductility and improved strength. As a result, numerous experimental studies have been carried out in recent years to examine the strength, the ultimate strain, and the postpeak stress relationship of fibre reinforced high strength confined concrete at ambient temperature [9-13]. Although reinforced concrete structures are generally considered to be resistant to fire, but the fire performance of these structural elements must be understood before they are used with confidence. Previous investigations have indicated that high strength concrete elements are susceptible to thermal spalling, loss of strength, and degradation of mechanical properties when subjected to rapid heating on rising in temperature [14-17]. The use of steel and polypropylene fibres has been recommended by most of the researchers to reduce and eliminate the risk of thermal spalling and also enhance the residual mechanical properties of high strength concrete at elevated temperature. The inclusion of polypropylene fibres in concrete takes benefits from porosity generated through melting of fibres and produces a finer residual capillary pores structure. Further, the addition of steel fibres may offer improvement in tensile strength of concrete to control crack formation and propagation and hence potentially improve the residual performance of concrete after exposure to high temperature [17-25]. The residual stress-strain response of confined concrete should be known to predict the postfire condition of concrete structures. Therefore, the knowledge of residual stress-strain model of confined fibre reinforced high strength concrete becomes important in case of structures 
built with such concrete. Many empirical models are available in the literature to predict the stress-strain curve of confined plain and fibre reinforced high strength concrete at room temperature [7-13]. However, the same cannot be applied due to the fact that the residual compressive strength of confined fibre reinforced high strength concrete decreases and strains increase considerably after an exposure to high temperature $[17,18]$. Thus, the available confinement models developed under ambient room temperature conditions would overestimate the strength and underestimate the strains if applied to heated confined fibre reinforced high strength concrete. The published data on the stress-strain modeling of confined concrete columns exposed to high temperatures are scarce. To the best of our knowledge, only three models have been developed in the past to estimate the compressive stress-strain curve of heated confined concrete [17, 26-30]. The critical review of the existing literature also indicates that there is no stress-strain model proposed in the past to estimate the postfire residual behaviour of confined fibrous high strength concrete. In view of this, a suitable stress-strain model is being proposed here, which shall be applicable to both circular confined high strength concrete and fibre reinforced high strength confined concrete after exposure to high temperature or postheated condition for different temperatures.

\section{Experimental Investigation}

Experimental evidence of a total of 105 compressed high strength reinforced concrete circular columns confined by lateral steel with and without fibres after exposure to high temperature was selected to study the residual stress-strain relationship of confined concrete. A summary of this previous experimental work with details of specimens and variables considered is given in Table 1. An experimental investigation has been carried out $[17,18]$, and it has been found that the variables significantly affect the behaviour of confined concrete at high temperature. Tests have shown that the residual postfire strength and strain capacities of confined fibre reinforced concrete were better than those of comparable confined nonfibre concrete.

\section{Model Comparison}

The experimental results of $\mathrm{CBH}$ series of high strength confined concrete after exposure to high temperature [17] were used for the validation of the best model among them [29, 30]. The predictions of the model along with experimental results of [17], and theoretical model of [3, 4] are presented in Figure 1(a). There are several models available in literature to represent the stress-strain behaviour of confined concrete at ambient temperature. In these two models one is Mander et al.s [4] model and the other is Scott et al.s [3] model, which were modified by [30], for stressed test at elevated temperature. In our study these modified models [30] are referred to as model 1 and model 2 . Model 3 was originally proposed by [29], on the basis of their experimental results of square high strength concrete confined column after exposure to high temperature for residual test method.
The existing analytical model of [30] agrees well with the experimental observations at lower temperature but it deviates sharply from the experimental results when the temperature increases. However, both results deviate widely from the experimental result with the increase of temperature. These models have limited validity in terms of concrete strength, section geometry, transverse reinforcement, and test conditions. The models of [30] are applicable to confined concrete in heated condition only and cannot be used to predict the postfire residual behaviour of confined concrete. Further, the residual stress-strain model of [29] was developed using the test data of square prisms of high strength concrete at elevated temperature. Therefore, the model may not be applicable to circular confinement column of high strength concrete. Similarly, both models were calibrated based upon the test data in which the cover spalling was not addressed and the contribution of the entire section including the cover was considered rather than accounting for the contribution of confined concrete only. Therefore, these models did not provide the exact behaviour of confined high strength concrete circular column at different temperatures. Further, due to the unavailability of experimental data of confined concrete at elevated temperature or when exposed to high temperature, high variability exists in the prediction of the postpeak stress and strain at different temperature which required further additional experimental results to justify the suitability of the models. However, it can be observed that the model prediction follows the experimental results very closely. The model provided better results than the previous models.

\section{Residual Stress-Strain Model for Confined Concrete}

The test results of $[17,18]$, show that the residual stress-strain characteristics of confined plain and fibre reinforced high strength concrete depend upon the characteristics of lateral confining steel, properties of fibres, and temperature of exposure. The effects of lateral confining steel and temperature have been taken into account by defining a nondimensional parameter $f_{l e T} / f^{\prime}{ }_{c}$, where, $f_{l e T}$ is the effective lateral confining pressure at peak confined stress of heated confined concrete. Parameter $f_{l e T} / f^{\prime}{ }_{c}$ has been designated as confinement index of heated transverse confining reinforcement, where $f_{l e T}$ is given by $f_{l e T}=K_{e} f_{l T}$. Following are the expressions for computing $K_{e}$ and $f_{l T}$ for heated confined concrete:

$$
\begin{aligned}
& K_{e}= \frac{\left(1-s^{\prime} / 2 c\right)}{\left(1-\rho_{c}\right)}, \\
& f_{l T}=\frac{1}{2} \rho_{s} f_{y h T}, \\
& \frac{f_{y T}}{f_{y}}=0.966+3.87 \times 10^{-4} T-1.08 \times 10^{-6} T^{2}, \\
& \text { For } 20<T \leq 800^{\circ} \mathrm{C},
\end{aligned}
$$

where $s^{\prime}$ is the clear spacing of ties, $\rho_{c}$ is the longitudinal reinforcement ratio in the core section, $c$ is the core diameter 


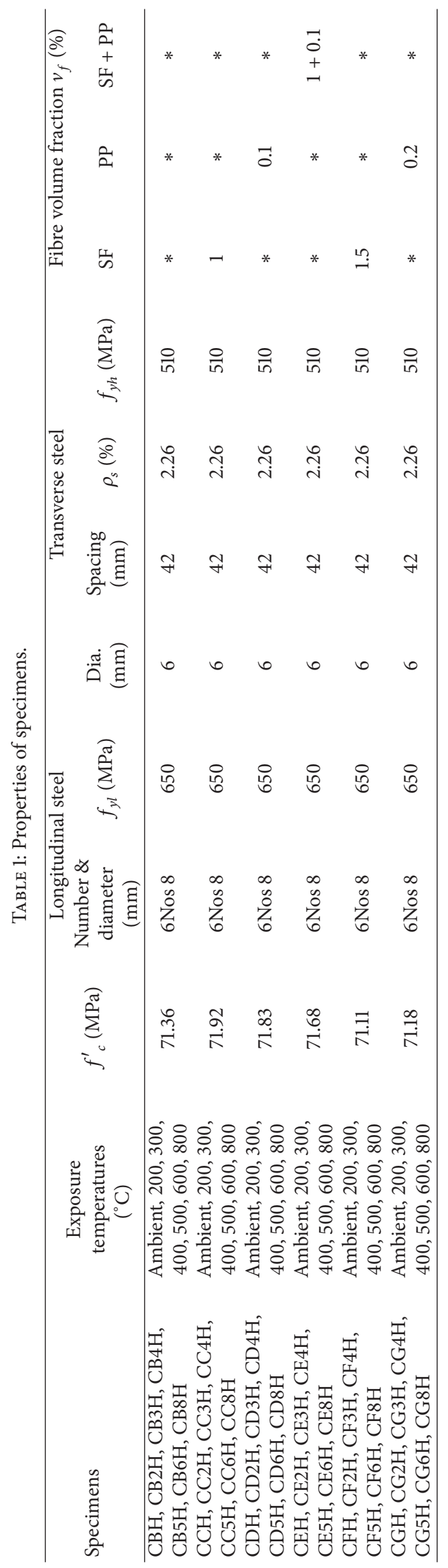



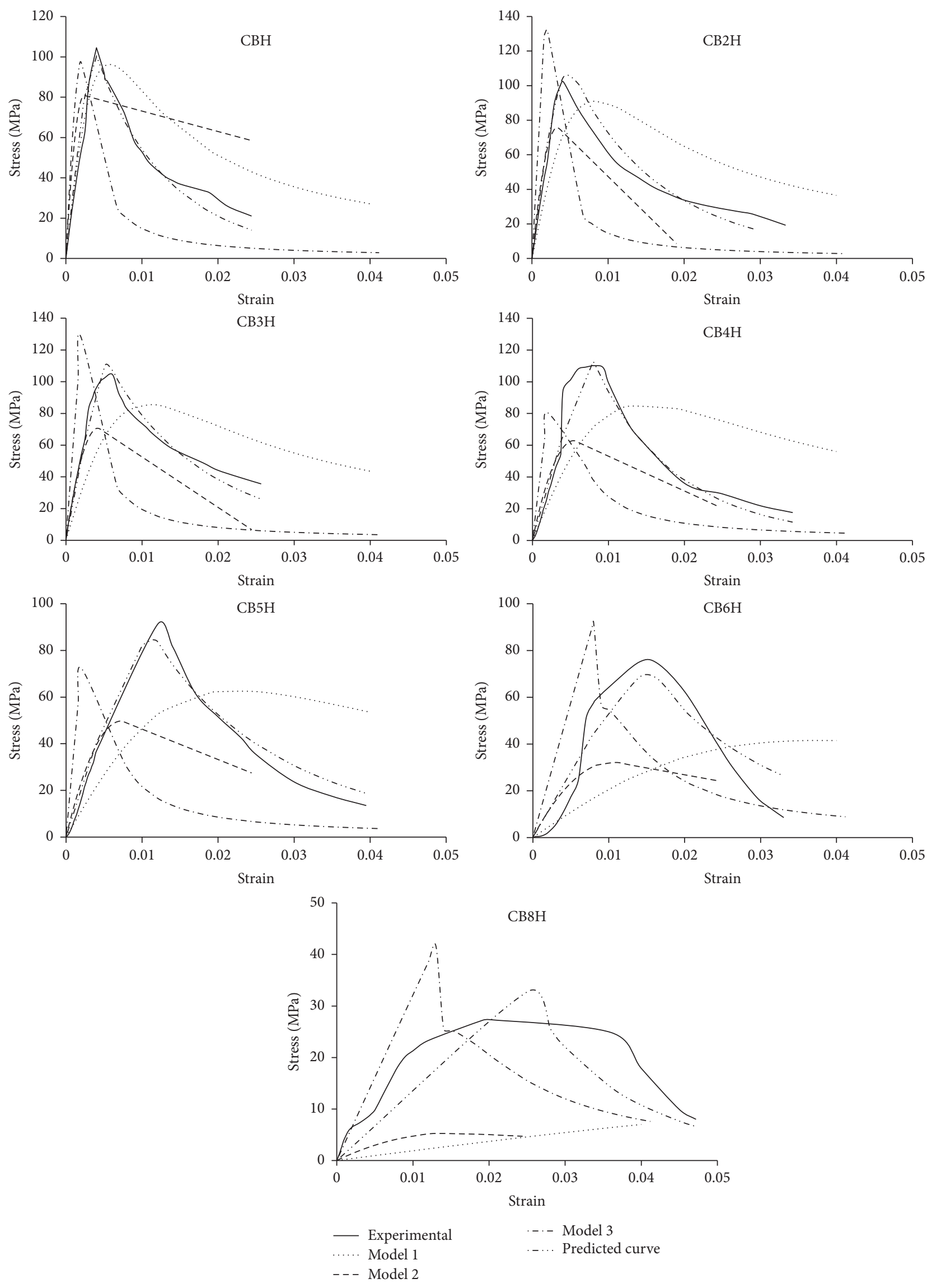

(a)

Figure 1: Continued. 

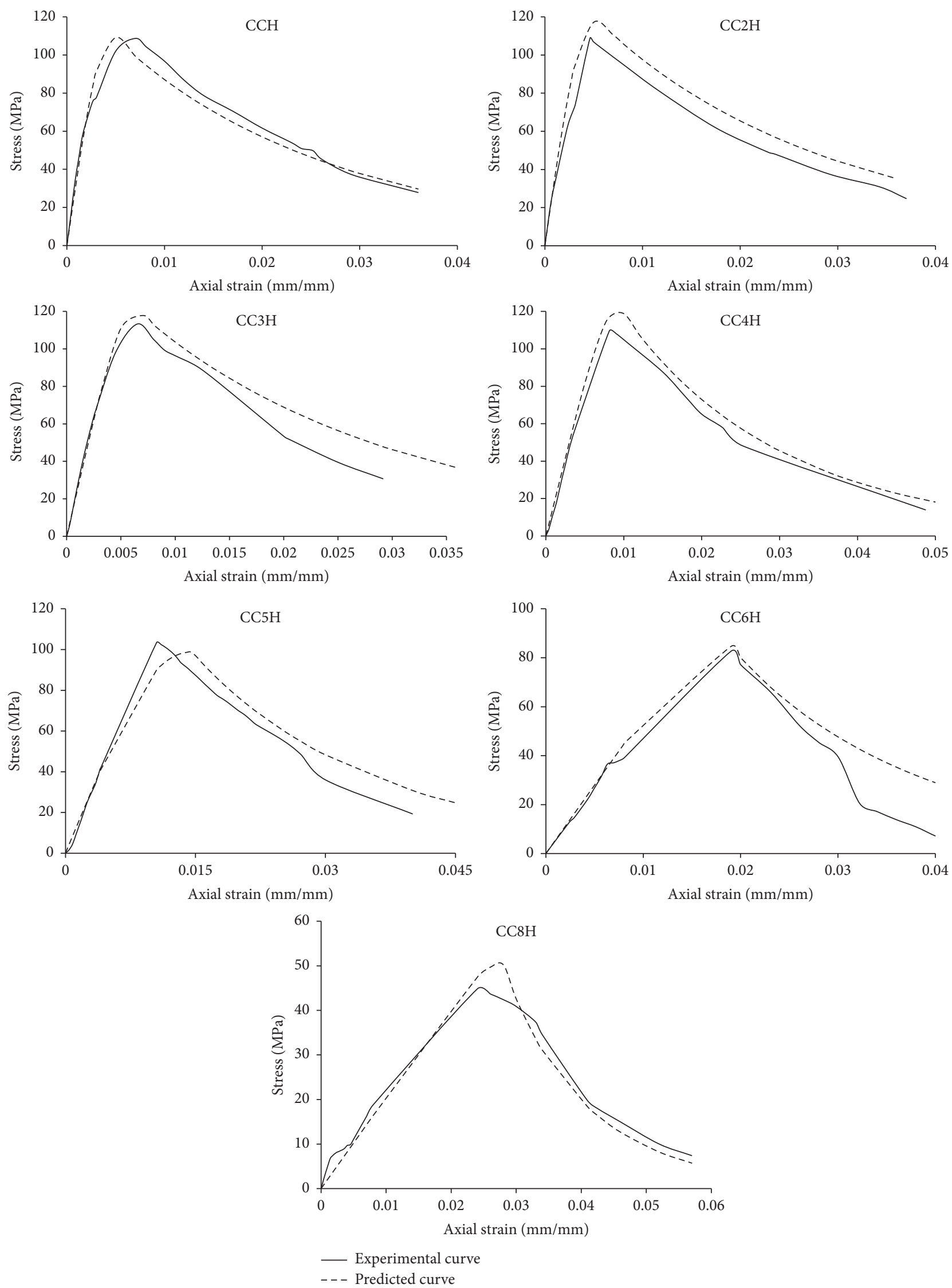

(b)

FIgURE 1: Continued. 

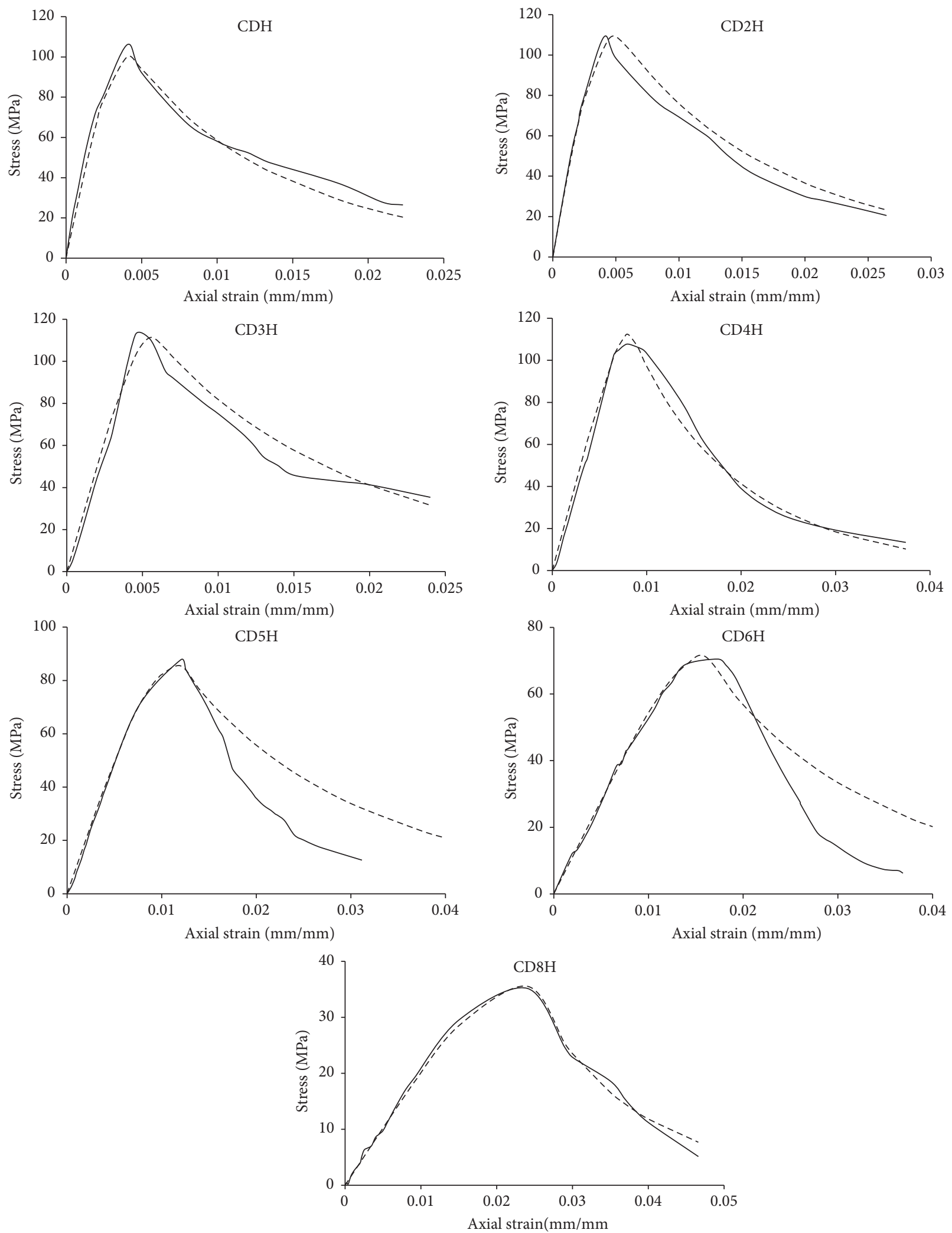

- Experimental curve
_- Predicted curve

(c)

FIgURE 1: Continued. 

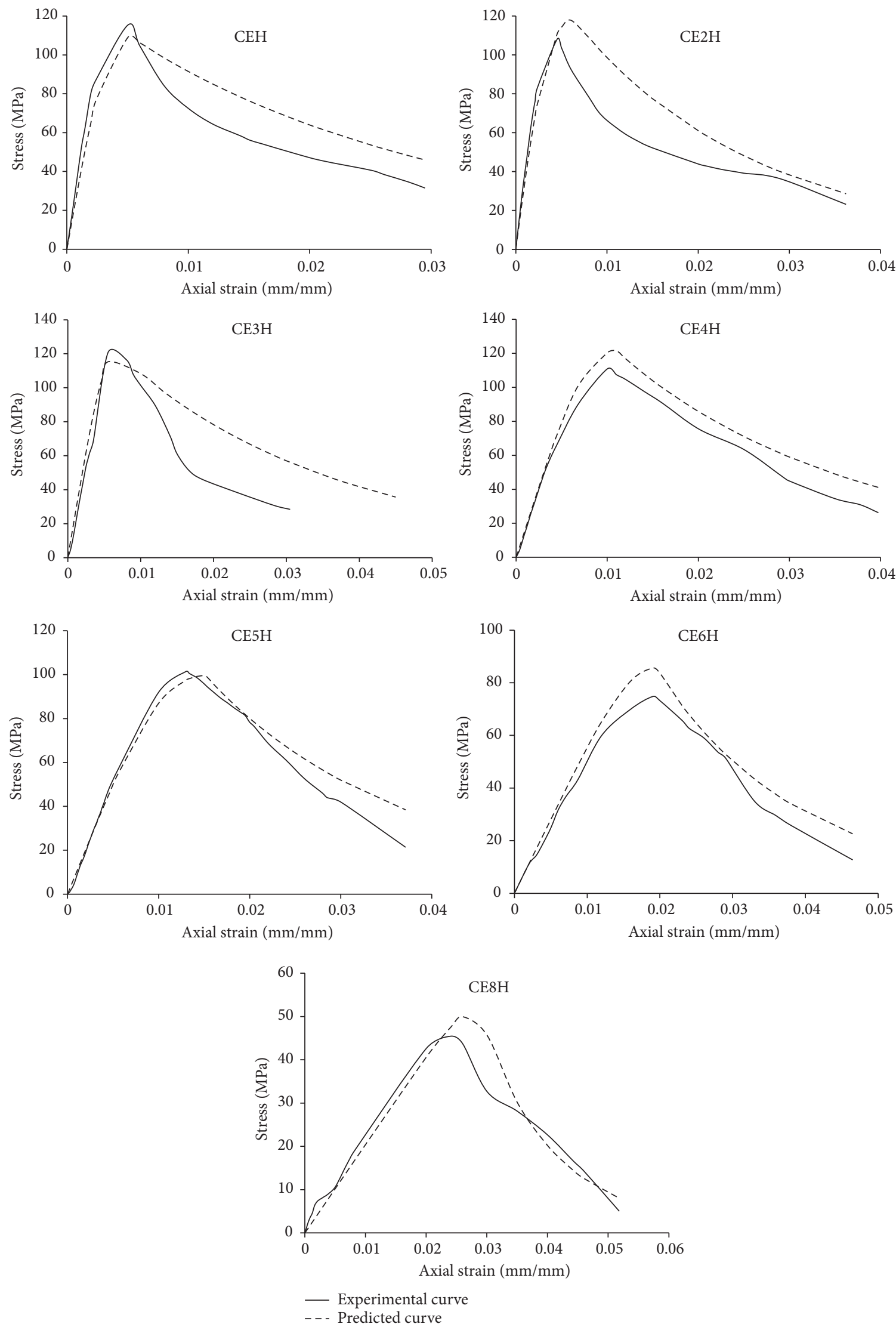

(d)

Figure 1: Continued. 

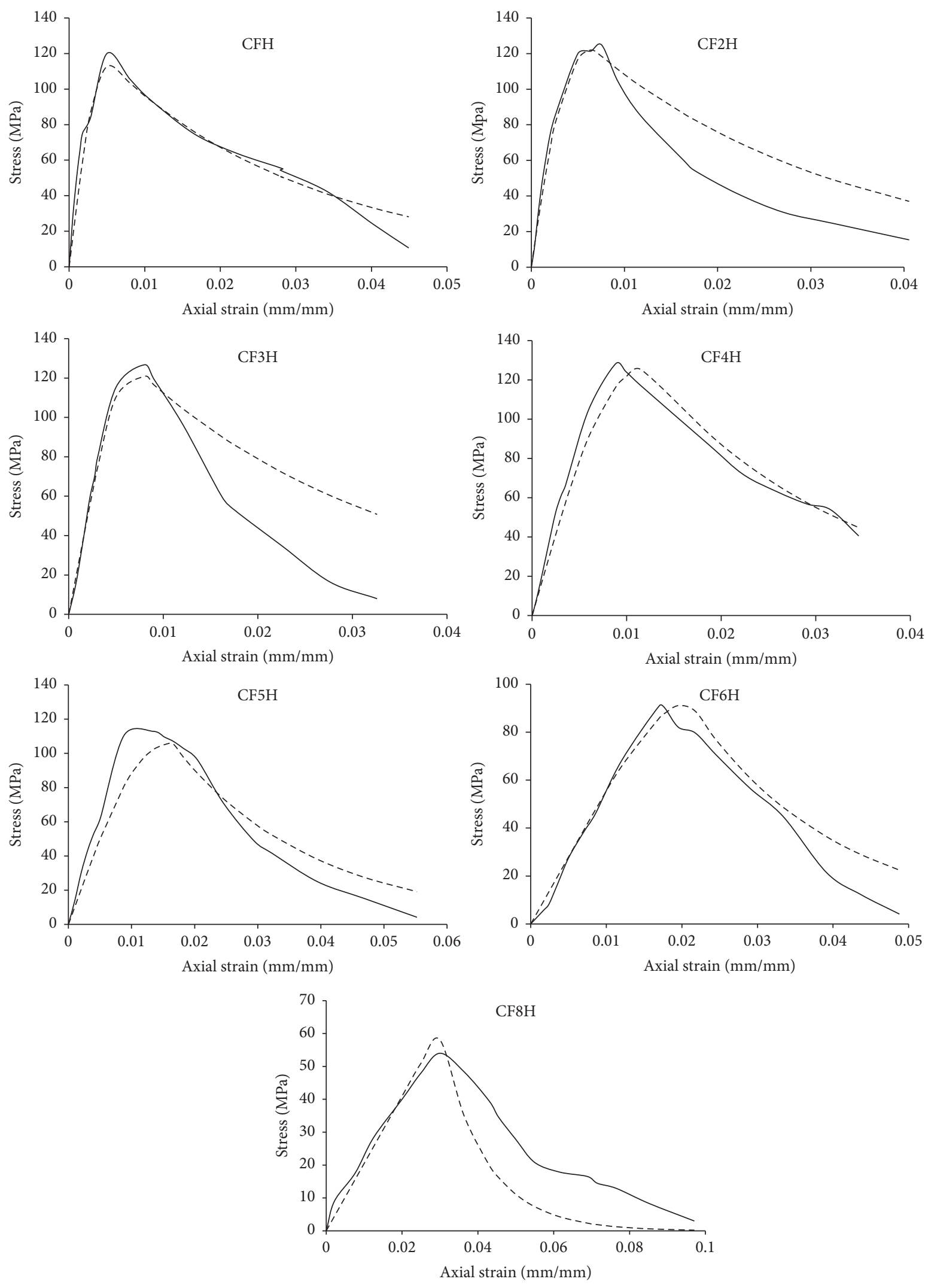

- Experimental curve

- - - Predicted curve

(e)

FIGURe 1: Continued. 

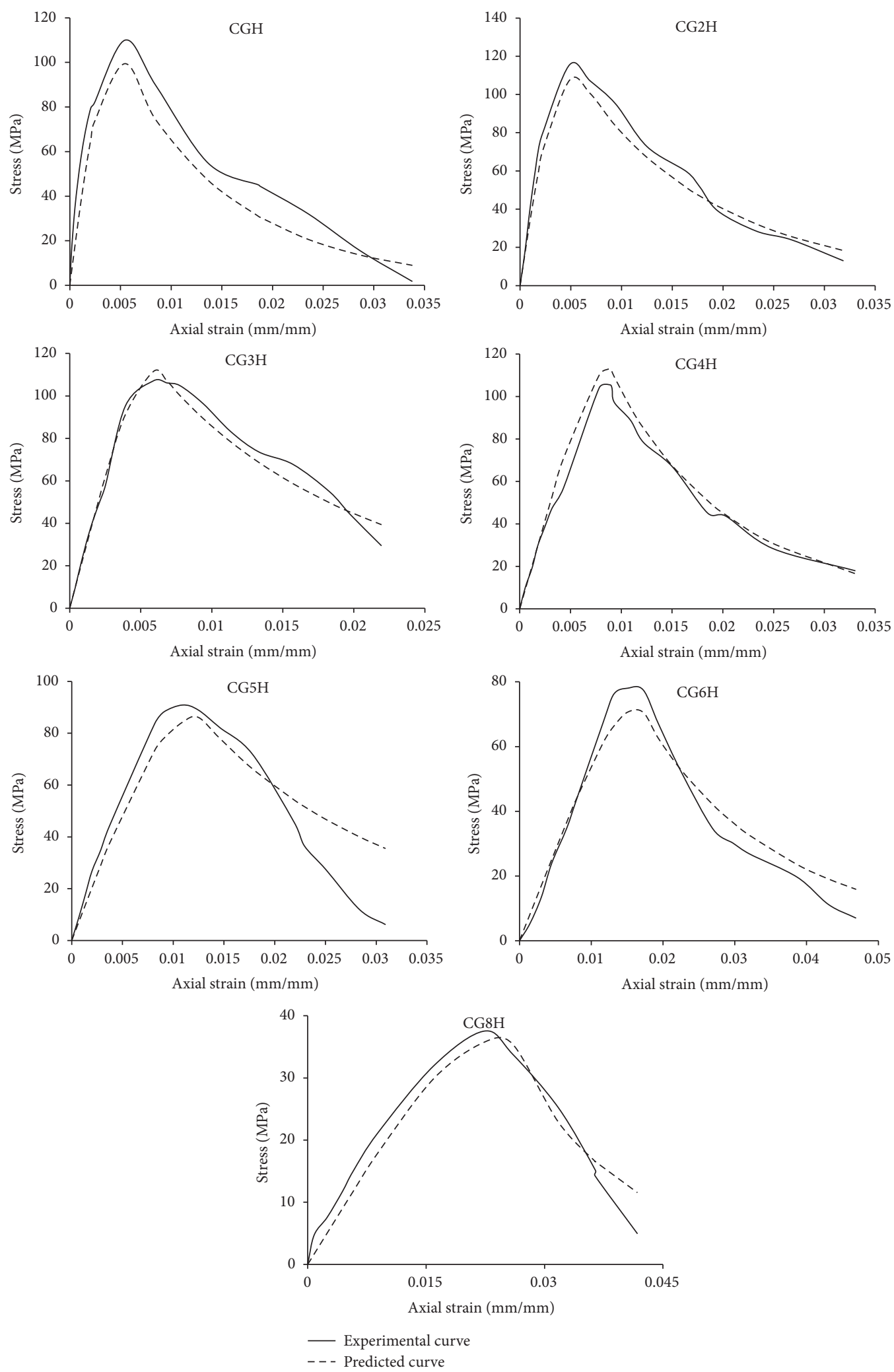

(f)

Figure 1: (a) Comparison of experimental and predicted residual stress-strain curves of CBH series specimens. (b) Comparison of experimental and predicted residual stress-strain curves of $\mathrm{CCH}$ series specimens. (c) Comparison of experimental and predicted residual stress-strain curves of $\mathrm{CDH}$ series specimens. (d) Comparison of experimental and predicted residual stress-strain curves of CEH series specimens. (e) Comparison of experimental and predicted residual stress-strain curves of CFH series specimens. (f) Comparison of experimental and predicted residual stress-strain curves of CGH series specimens. 
$c / c$ of perimeter tie, $\rho_{s}$ is the volumetric ratio of confining tie steel, and $f_{y h T}$ is the residual yield strength of confining reinforcing bars heated to a temperature $T^{\circ} \mathrm{C}$. In the case of laterally confined high strength concrete specimens in the presence of fibres, it was observed from the experimental data that the addition of fibres tends to further increase the strength and deformability of concrete as compared to the case of transverse reinforcement alone. Thus, the various parameters of the proposed model have been related to the reinforcing index, RI, of fibres to take into account the effect of introducing fibres in HSC mix, where reinforcing index $\mathrm{RI}=w_{f}\left(l_{f} / d\right)$. The experimental results have indicated that the steel and polypropylene fibres affect the stress-strain behaviour of confined concrete differently. Therefore, the various parameters were calibrated in terms of both the reinforcing indices of steel fibres $(\mathrm{RI})_{S}$ and polypropylene fibres $(\mathrm{RI})_{P}$ to incorporate their individual effects by carrying out a multiple regression analysis.

The stress-strain model being proposed here has been defined in terms of confined strength, $f_{c c}$, corresponding strain, $\varepsilon_{c c}$, and the postpeak strain, $\varepsilon_{c 50 c}$. An analysis of the overall test data from the present study shows that the inclusion of fibres, especially steel fibres, in concrete causes enhancements in strength and deformability of confined HSC and provides indirect confinement to concrete. While the effect of confinement due to the lateral reinforcement and the influence of temperature could be incorporated by the confinement index $f_{l e T} / f_{c}^{\prime}$, the indirect confinement of fibres was accounted by defining an equivalent index $k_{f} / f_{c}^{\prime}$ for fibres, where parameter $k_{f}$ represents the indirect lateral confining pressure provided by the fibres. Parameter $k_{f}$ has been related empirically to the reinforcing index of fibres and temperature of exposure. Based upon the observations from the test data, it is reasonable to assume that the contribution of any given fibre towards the strength enhancement shall be different from that of strain capacities. Therefore, different expressions have been proposed for $k_{f}$ in deriving the equations of parameters $f_{c c}, \varepsilon_{c c}, \varepsilon_{c 50 c}$ of stress-strain curve. The following equations for residual maximum confined stress, $f_{c c}$, corresponding strain, $\varepsilon_{c c}$, and the postpeak strain, $\varepsilon_{c 50 c}$, were derived by carrying out multiple regression analysis:

(1) Expression for peak confined stress:

$$
\frac{f_{c c}}{f_{c}^{\prime}}=11.59\left[\frac{f_{l e T}}{f_{c}^{\prime}}+\frac{k_{f 1}}{f_{c}^{\prime}}\right]^{0.85}-0.164
$$

(2) Expression for peak confined strain:

$$
\frac{\varepsilon_{c c}}{\varepsilon_{c o}}=149.83\left[\frac{f_{l e T}}{f_{c}^{\prime}}+\frac{k_{f 2}}{f^{\prime}{ }_{c}}\right]^{1,75}-0.128 .
$$

(3) Expression for strain at $50 \%$ of peak confined stress in descending side:

$$
\frac{\varepsilon_{c 50 c}}{\varepsilon_{c o}}=175\left[\frac{f_{l e T}}{f^{\prime}{ }_{c}}+\frac{k_{f 3}}{f^{\prime}{ }_{c}}\right]^{0.051}-151.53,
$$

where coefficients $k_{f 1}(\mathrm{MPa}), k_{f 2}(\mathrm{MPa})$, and $k_{f 3}(\mathrm{MPa})$ quantify the lateral confining pressure contributed by the steel fibres towards residual confined strength, $f_{c c}$, corresponding strain, $\varepsilon_{c c}$, and the postpeak strain, $\varepsilon_{c 50 c}$, respectively. They are defined as follows:

$$
\begin{gathered}
k_{f 1}=1.457+0.00269 T+0.985(\mathrm{RI})_{S}+0.052(\mathrm{RI})_{P}, \\
\text { for } 20<T \leq 400^{\circ} \mathrm{C} \\
k_{f 1}=3.55-0.00545 T+1.56(\mathrm{RI})_{S}+0.42(\mathrm{RI})_{P}, \\
\text { for } 400<T \leq 800^{\circ} \mathrm{C} \\
k_{f 2}=0.92+0.0037 T+1.06(\mathrm{RI})_{S}+1.63(\mathrm{RI})_{P}, \\
\text { for } 20<T \leq 300^{\circ} \mathrm{C} \\
k_{f 2}=-5.70+0,041 T+2.32(\mathrm{RI})_{S}+1.66(\mathrm{RI})_{P}, \\
\text { for } 300<T \leq 800^{\circ} \mathrm{C} \\
k_{f 3}=1.98+0.0068 T+9.91(\mathrm{RI})_{S}+3.82(\mathrm{RI})_{P}, \\
\text { for } 20<T \leq 400^{\circ} \mathrm{C} \\
k_{f 3}=-10.206+0.043 T+9.76(\mathrm{RI})_{S}+10.82(\mathrm{RI})_{P}, \\
\text { for } 400<T \leq 800^{\circ} \mathrm{C} .
\end{gathered}
$$

Figures 2(a)-2(c) compare the experimental results with the proposed model predictions from the above expressions. The ascending branch of the stress-strain curve is based on the relationship originally proposed by [31] and later considered by $[12,32-34]$ to predict the ascending part of the confined concrete at ambient conditions. In the proposed model, the same expression has been modified to predict the ascending branch of the stress-strain curve of heated confined concrete. Further, an examination of the test curves indicated that the residual stress-strain curve of both plain and fibre reinforced confined high strength concrete can be correctly predicted by the following expressions. It can be seen that the analytical predictions are in good agreement with the test values.

$$
f_{c}=f_{c c}\left[\frac{k\left(\varepsilon_{c} / \varepsilon_{c c}\right)}{k-1+\left(\varepsilon_{c} / \varepsilon_{c c}\right)^{k}}\right] \quad \varepsilon_{c} \leq \varepsilon_{c c},
$$

where

$$
k=\frac{E_{c i T}}{E_{c i T}-\left(f_{c c} / \varepsilon_{c c}\right)} .
$$

$E_{c i T}$ is the initial tangent modulus of elasticity of heated confined plain and fibrous high strength concrete and is computed by

$$
\begin{aligned}
& \frac{E_{c i T}}{E_{c i}}=1 \quad \text { for } 20<T \leq 200^{\circ} \mathrm{C} \\
& \frac{E_{c i T}}{E_{c i}}=1.76-4.29 \times 10^{-3} \mathrm{~T}+2.7 \times 10^{-6} T^{2}
\end{aligned}
$$




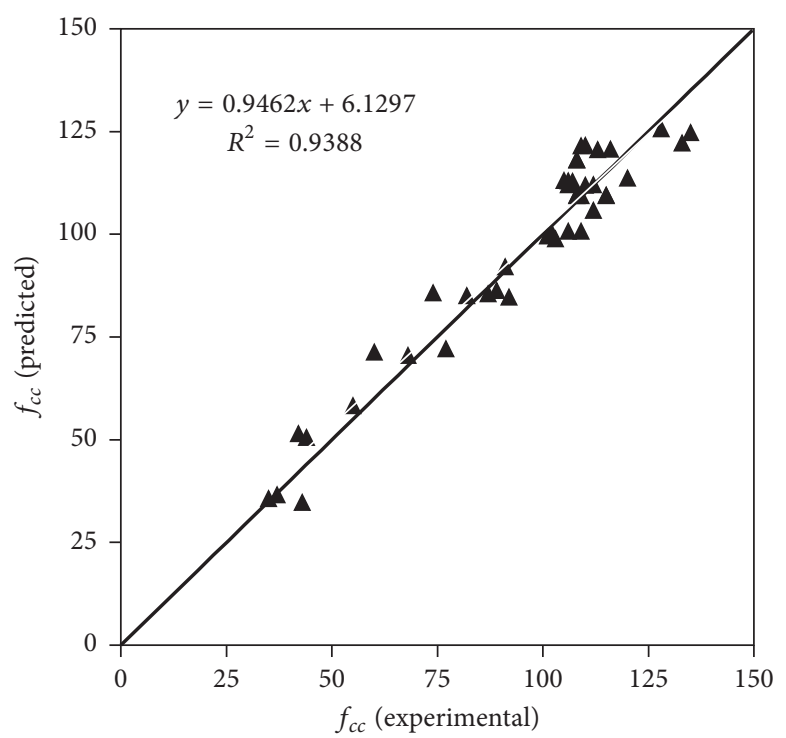

(a)

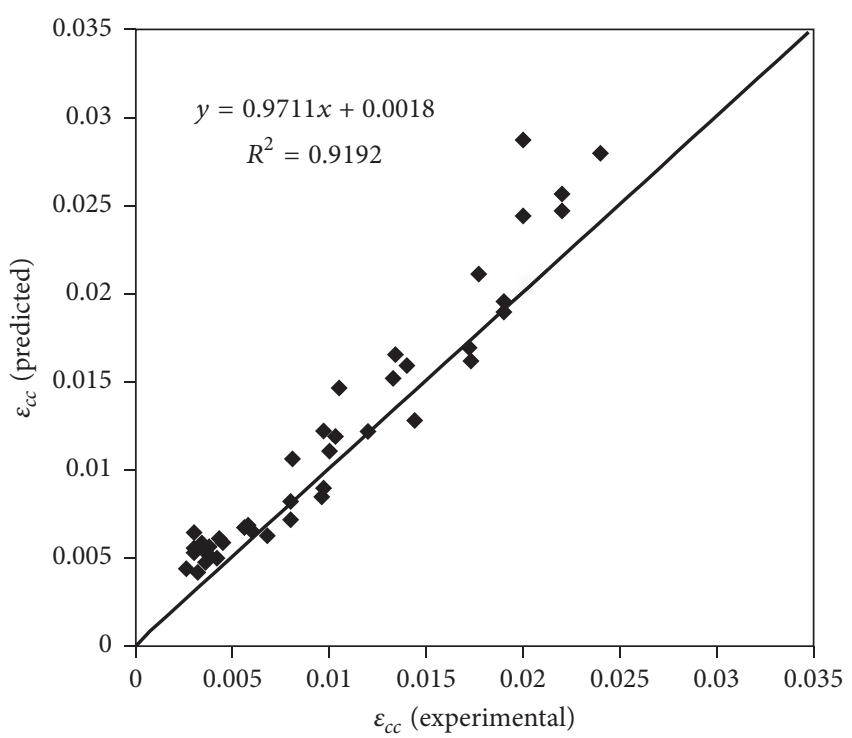

(b)

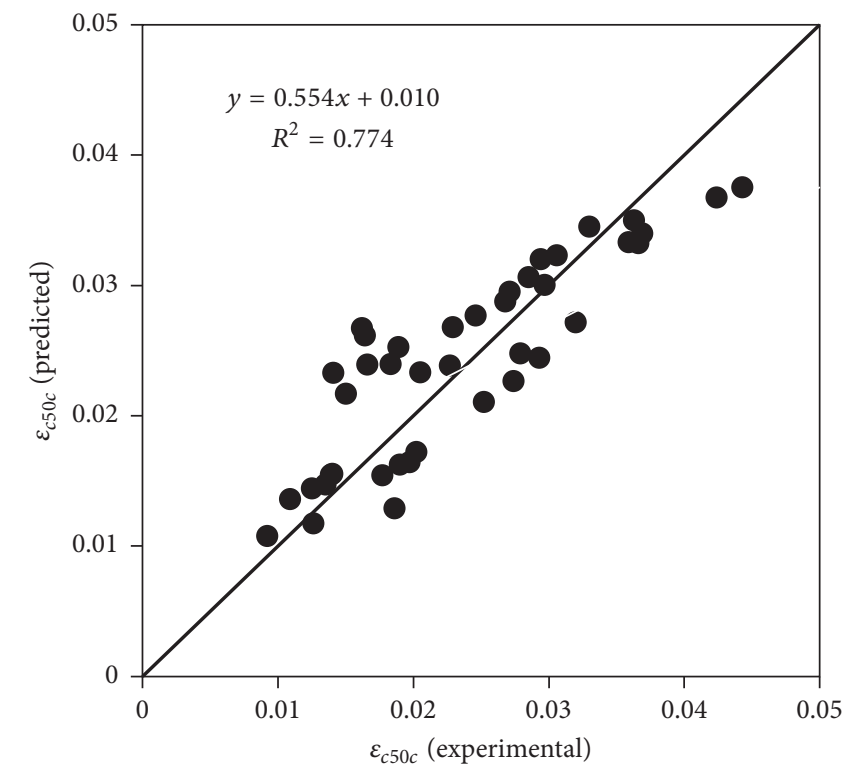

(c)

Figure 2: (a) Prediction of peak stress of confined concrete. (b) Prediction of strain in confined concrete at peak stress. (c) Prediction of postpeak strain of confined concrete at $50 \%$ of peak stress.

where $E_{c i}$ is the initial tangent modulus of elasticity of confined HSC at ambient temperature. The descending branch is given by

$$
f_{c}=f_{c c} \exp \left[k_{1}\left(\varepsilon_{c}-\varepsilon_{c c}\right)^{k_{2}}\right], \quad \varepsilon_{c} \geq \varepsilon_{c c}
$$

where $k_{1}$ and $k_{2}$ are the coefficients which control the general slope and curvature of the descending branch, respectively. The expressions for $k_{1}$ and $k_{2}$ are given by

$$
k_{1}=\frac{\ln 0.5}{\left(\varepsilon_{c 50 c}-\varepsilon_{c c}\right)^{k_{2}}} .
$$

Though the above equations have also the same basic form as proposed by [12, 33, 34], for confined concrete at ambient temperature, coefficient $k_{2}$ has been recalibrated on the present test data in order to correctly predict the postpeak portion of the residual stress-strain curves of the confined concrete exposed to elevated temperatures. The following expressions are proposed for $k_{2}$ :

$$
\begin{aligned}
k_{2} & =3.11\left[\frac{f_{l e T}}{f^{\prime}{ }_{c}}+\frac{k_{f 4}}{f^{\prime}{ }_{c}}\right]^{0.043}-1.88 \\
k_{f 4} & =1.27+0.00222 T+3.32(\mathrm{RI})_{S}+2.64(\mathrm{RI})_{P},
\end{aligned}
$$

for $20<T \leq 400^{\circ} \mathrm{C}$ 


$$
\begin{aligned}
& k_{f 4}=1.116+0.0024 T+3.38(\mathrm{RI})_{S}+1.81(\mathrm{RI})_{P} \text {, } \\
& \text { for } 400<T \leq 800^{\circ} \mathrm{C} \text {. }
\end{aligned}
$$

\section{Verification of the Proposed Model}

By redefining the different parameters in (1)-(11) the change in the shape of the stress-strain curves for the postheated fibrous confined concrete with different temperatures could be considered. However, to verify the validity of the proposed model, Figures 1(a)-1(f) show the comparison of analytical stress-strain curves with the experimental stress-strain curves of all the specimens. It can be observed that the agreement between the predicted and the experimental stressstrain curves is quite reasonable.

\section{Conclusions}

Analytical model for concrete confinement by rectilinear reinforcement at different exposure temperatures proposed by various researchers was studied. All three models were applied to high strength confined concrete specimens of $\mathrm{CBH}$ series. However no model provided the most accurate prediction for the stress-strain curve of high strength confined circular column at different temperature. Therefore, a model for representative postfire behaviour of high strength confined concrete and high strength fibre reinforced confined concrete was proposed. The following conclusions were drawn from this work. The models proposed by [29], for residual test method, and [30], for stress test method, underestimate the residual compressive strength of confined high strength concrete at high temperature in all the specimens. Therefore, a complete lack of agreement on the stress-strain behaviour is found between experimental and analytical results. However, limited work is reported; therefore, additional experimental test results at different temperature are needed to investigate the role of compressive strength of confined concrete, geometrical shape, test methods, and validity of the models. Further, the proposed model is able to generate a complete residual compressive stress-strain curve for both high strength confined concrete and high strength fibre reinforced confined concrete after exposure to high temperature. Good agreements are observed between proposed empirical equations and experimental results for residual stress-strain curves in all the specimens at different temperatures.

\section{Notations}

$A_{c}$ : Cross-sectional area of concrete in the column specimen section

$A_{c c}$ : Cross-sectional area of core concrete in the column specimen section

$A_{\text {cuc }}$ : Area under the stress-strain curve of confined concrete

$A_{\text {cuo }}$ : Area under the stress-strain curve of unconfined concrete

$A_{g}$ : Gross area of column cross section
Delta $T$ :

E:

$E_{T}:$

$E_{c i}:$

$E_{c i T}:$

$f_{c}:$

$f_{c}^{\prime}$ :

$f_{c c}$ :

$f_{c o}$ :

$f_{i}$ :

$f_{l}:$

$f_{l e}:$

$f_{l e T}$ :

$f_{l T}$ :

$f_{y h}:$

$f_{y l}$ :

$f_{y T}$ :

$K_{e}:$

$P_{c}$ :

$P_{c c}$ :

$P_{\max }$ :

$P_{o}$ :

$P_{o c}$ :

$P_{\text {occ }}$ :

$s:$

$s^{\prime}:$

T:

$\varepsilon_{c}$ :

$\varepsilon^{\prime}:$

$\varepsilon^{\prime}{ }_{c}$ :

$\mathcal{E}_{c 50 c}$ :

$\mathcal{E}_{c 85 c}$ :

$\varepsilon_{c c}:$

$\varepsilon_{c o \text { (Room Temp) }}$ :
Gross sectional area of longitudinal steel

Cross-sectional area of a tie bar

Core diameter centre to centre of parameter tie

Temperature difference between surface and centre of specimen

Young's modulus of steel bars at ambient temperature

Elastic modulus of steel bars exposed to elevated temperature

Initial tangent modulus of elasticity of confined concrete

Initial tangent modulus of elasticity of heated confined concrete

Any stress value on the stress-strain curve

Standard cylinder compressive strength of plain concrete on the day of testing

Peak stress of confined concrete

Compressive strength of unconfined

concrete

Stress at the inflection point of confined concrete stress-strain curve

Nominal average lateral confining pressure acting on the core concrete

Effective lateral confining pressure at peak confined stress

Effective lateral confining pressure acting on the core concrete after being exposed to high temperature

Nominal lateral confining pressure in heated concrete

Yield strength of lateral confining steel

Yield strength of longitudinal reinforcement Residual yield strength of reinforcing bar after being exposed to high temperature Confinement effectiveness coefficient Peak concrete load in the load-strain curve after deducting the contribution of steel Peak confined concrete load

Maximum total applied load on the confined concrete column specimen

Theoretical concentric capacity of specimen

Gross concrete area force

Core concrete area force

Centre to centre spacing of confining ties

Clear spacing of ties

Exposed temperature $\left({ }^{\circ} \mathrm{C}\right)$

Any strain value on the stress-strain curve

Axial strain corresponding to $P_{\max }$

Axial strain corresponding to the stress, $f_{c}^{\prime}$, of standard plain concrete cylinder

Axial strain at which the load drops to $50 \%$

of the peak confined concrete load

Axial strain at which the load drops to $85 \%$

of the peak confined concrete load

Axial strain at peak confined load $P_{c c}$

: Strain at peak load of unconfined concrete specimen at ambient temperature 
$\varepsilon_{c o}:$ Strain at peak load of unconfined concrete specimen exposed to elevated temperature

$\rho_{c}$ : Longitudinal reinforcement ratio in the core section

$\rho_{l}$ : Volumetric ratio of longitudinal steel

$\rho_{s}$ : Volumetric ratio of transverse reinforcement.

\section{Competing Interests}

The authors declare that there is no conflict of interests regarding the publication of this paper.

\section{References}

[1] D. Cusson and P. Paultre, "High-strength concrete columns confined by rectangular ties," Journal of Structural Engineering, vol. 120, no. 3, pp. 783-804, 1994.

[2] B. Li, R. Park, and H. Tanaka, "Strength and ductility of reinforced concrete members and frames constructed using high strength concrete," Research Report 94-5, University of Canterbury, Christchurch, New Zealand, 1994.

[3] B. D. Scott, R. Park, and M. J. N. Priestley, "Stress-strain behaviour of concrete confined by overlapping hoops at high and low strain rates," Journal of the American Concrete Institute, vol. 79, no. 1, pp. 13-27, 1982.

[4] J. B. Mander, M. J. Priestley, and R. Park, "Theoretical stressstrain model for confined concrete," Journal of Structural Engineering, vol. 114, no. 8, pp. 1804-1826, 1988.

[5] S. R. Razvi and M. Saatcioglu, "Strength and deformability of confined high-strength concrete columns," ACI Structural Journal, vol. 91, no. 6, pp. 678-687, 1994.

[6] S. A. Sheikh and S. M. Uzumeri, "Strength and ductility of tied concrete columns," ASCE Journal of Structural Division, vol. 106, no. 5, pp. 1079-1102, 1980.

[7] B. Campione, S. Mindess, and G. Zingone, "Compressive stress-strain behavior of normal and high-strength carbon-fiber concrete reinforced with steel spirals," ACI Materials Journal, vol. 96, no. 1, pp. 27-34, 1999.

[8] S. J. Foster and M. M. Attard, "Strength and ductility of fiberreinforced high-strength concrete columns," Journal of Structural Engineering, vol. 127, no. 1, pp. 28-34, 2001.

[9] L. S. Hsu and C. T. Hsu, "Stress-strain behavior of steel fiber high strength concrete under compression," ACI Structural Journal, vol. 91, no. 4, pp. 448-457, 1994.

[10] H. C. Lima Jr., S. M. B. A. Da Silva, and J. S. Giongo, "Steel fibre high strength concrete prisms confined by rectangular ties under concentric compression," Journal of Materials and Structures, vol. 37, no. 274, pp. 689-697, 2004.

[11] M. A. Mansur, M. S. Chin, and T. H. Wee, "Stress-strain relationship of confined high-strength plain and fiber concrete," Journal of Materials in Civil Engineering, vol. 9, no. 4, pp. 171179, 1997.

[12] U. Sharma, P. Bhargava, and S. K. Kaushik, "Comparative study of confinement models for high-strength concrete columns," Magazine of Concrete Research, vol. 57, no. 4, pp. 185-197, 2005.

[13] U. K. Sharma, P. Bhargava, and S. A. Sheikh, "Tie-confined fibrereinforced high-strength concrete short columns," Magazine of Concrete Research, vol. 59, no. 10, pp. 757-769, 2007.

[14] F.-P. Cheng, V. K. R. Kodur, and T.-C. Wang, "Stress-strain curves for high strength concrete at elevated temperatures,"
Journal of Materials in Civil Engineering, vol. 16, no. 1, pp. 84-90, 2004.

[15] Y. F. Chang, Y. H. Chen, M. S. Sheu, and G. C. Yao, "Residual stress-strain relationship for concrete after exposure to high temperatures," Cement and Concrete Research, vol. 36, no. 10, pp. 1999-2005, 2006.

[16] L. T. Phan and N. J. Carino, "Review of mechanical properties of HSC at elevated temperature," Journal of Materials in Civil Engineering, vol. 10, no. 1, pp. 58-64, 1998.

[17] U. K. Sharma, K. A. Zaidi, and N. M. Bhandari, "Strength and deformability of heated confined fibrous concrete," Magazine of Concrete Research, vol. 64, no. 7, pp. 631-646, 2012.

[18] K. A. Zaidi, U. K. Sharma, P. Bhargava, and N. M. Bhandari, "Uni-axial behaviour of confined fiber reinforced high strength concrete exposed to elevated temperatures," in Proceedings of the 6 th International Conference on Structures in Fire (SiF '10), pp. 817-825, Michigan State University, June 2010.

[19] F. Aslani and B. Samali, "Constitutive relationships for steel fibre reinforced concrete at elevated temperatures," Fire Technology, vol. 50, no. 5, pp. 1249-1268, 2014.

[20] C.-G. Han, Y.-S. Hwang, S.-H. Yang, and N. Gowripalan, "Performance of spalling resistance of high performance concrete with polypropylene fiber contents and lateral confinement," Cement and Concrete Research, vol. 35, no. 9, pp. 1747-1753, 2005.

[21] A. Lau and M. Anson, "Effect of high temperatures on high performance steel fibre reinforced concrete," Cement and Concrete Research, vol. 36, no. 9, pp. 1698-1707, 2006.

[22] C. S. Poon, Z. H. Shui, and L. Lam, "Compressive behavior of fiber reinforced high-performance concrete subjected to elevated temperatures," Cement and Concrete Research, vol. 34, no. 12, pp. 2215-2222, 2004.

[23] K. K. Sideris, P. Manita, and E. Chaniotakis, "Performance of thermally damaged fibre reinforced concretes," Construction and Building Materials, vol. 23, no. 3, pp. 1232-1239, 2009.

[24] S. L. Suhaendi and T. Horiguchi, "Effect of short fibers on residual permeability and mechanical properties of hybrid fibre reinforced high strength concrete after heat exposition," Cement and Concrete Research, vol. 36, no. 9, pp. 1672-1678, 2006.

[25] J. Xiao and H. Falkner, "On residual strength of high-performance concrete with and without polypropylene fibres at elevated temperatures," Fire Safety Journal, vol. 41, no. 2, pp. 115-122, 2006.

[26] U. K. Sharma, K. A. Zaidi, P. Bhargava, and N. M. Bhandari, "Residual strength and deformation characteristics of confined concrete subjected to elevated temperature," in Proceedings of the 9th U.S. National and 10th Canadian Conference on Earthquake Engineering, pp. 2178-2187, Toronto, Canada, July 2010.

[27] V. K. R. Kodur and R. McGrath, "Effect of silica fume and lateral confinement on fire endurance of high strength concrete columns," Canadian Journal of Civil Engineering, vol. 33, no. 1, pp. 93-102, 2006.

[28] M. J. Terro and S. A. Hamoush, "Effect of confinement on siliceous aggregate concrete subjected to elevated temperatures and cyclic heating," ACI Materials Journal, vol. 94, no. 2, pp. 83-89, 1997.

[29] B. Wu, X. P. Su, H. Li, and J. Yuan, "Effects of high temperature on residual mechanical properties of confined and unconfined high strength concrete," ACI Material Journal, vol. 99, no. 4, pp. 399-407, 2002. 
[30] M. A. Youssef and M. Moftah, "General stress-strain relationship for concrete at elevated temperatures," Engineering Structures, vol. 29, no. 10, pp. 2618-2634, 2007.

[31] S. Popovics, "A numerical approach to the complete stress-strain curve of concrete," Cement and Concrete Research, vol. 3, no. 5, pp. 583-599, 1973.

[32] D. Cusson and P. Paultre, "Stress-strain model for confined high-strength concrete," Journal of Structural Engineering, vol. 121, no. 3, pp. 468-477, 1995.

[33] F. Légeron and P. Paultre, "Uniaxial confinement model for normal- and high-strength concrete columns," Journal of Structural Engineering, vol. 129, no. 2, pp. 241-252, 2003.

[34] P. Paultre, R. Eid, Y. Langlois, and Y. Lévesque, "Behavior of Steel Fiber-Reinforced High-Strength Concrete Columns under Uniaxial Compression," Journal of Structural Engineering, vol. 136, no. 10, pp. 1225-1235, 2010. 


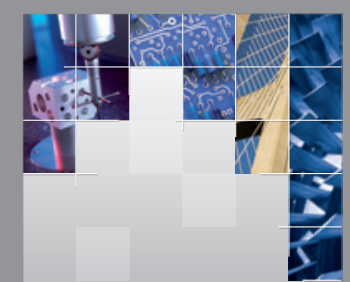

\section{Enfincering}
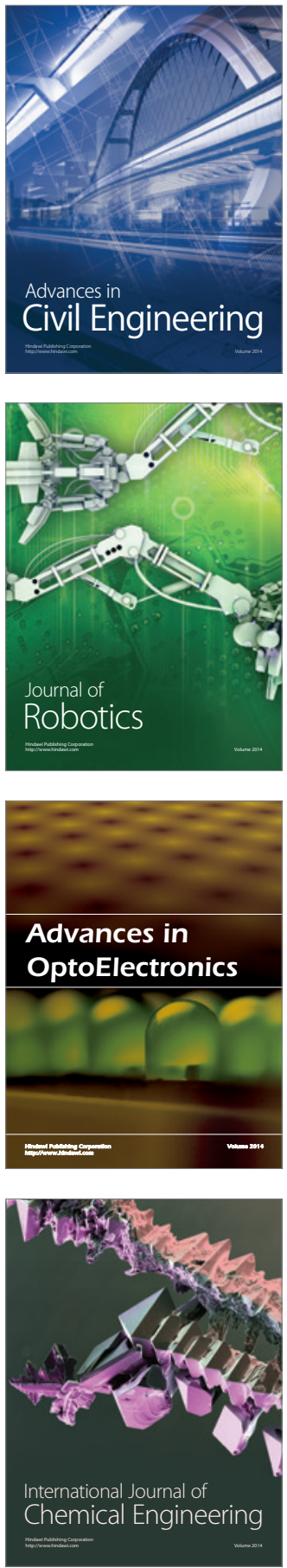

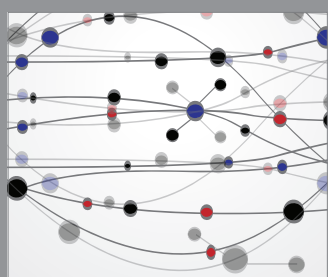

The Scientific World Journal

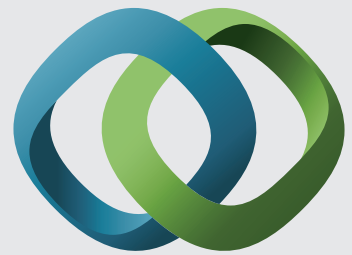

\section{Hindawi}

Submit your manuscripts at

http://www.hindawi.com
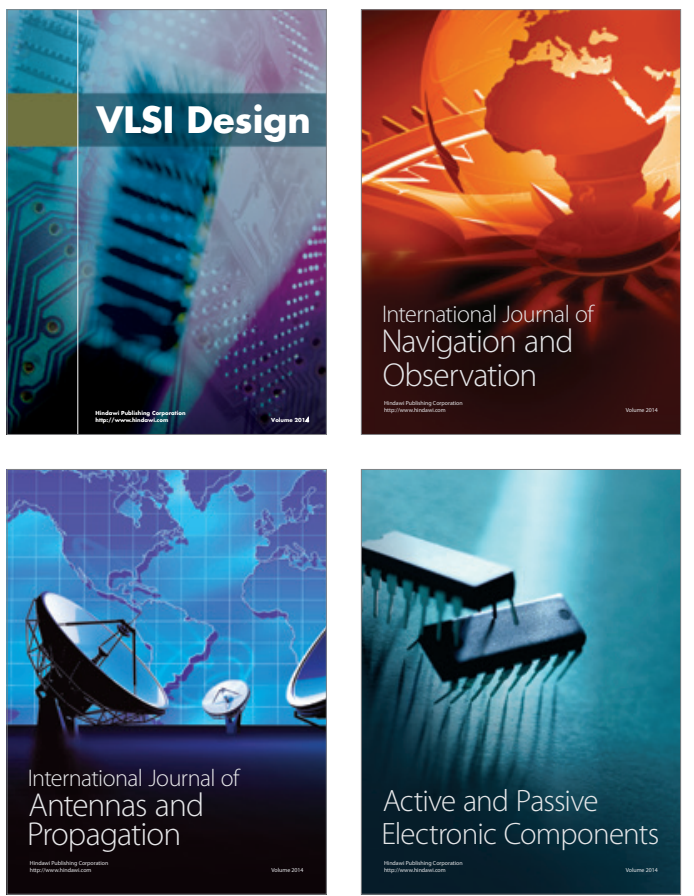
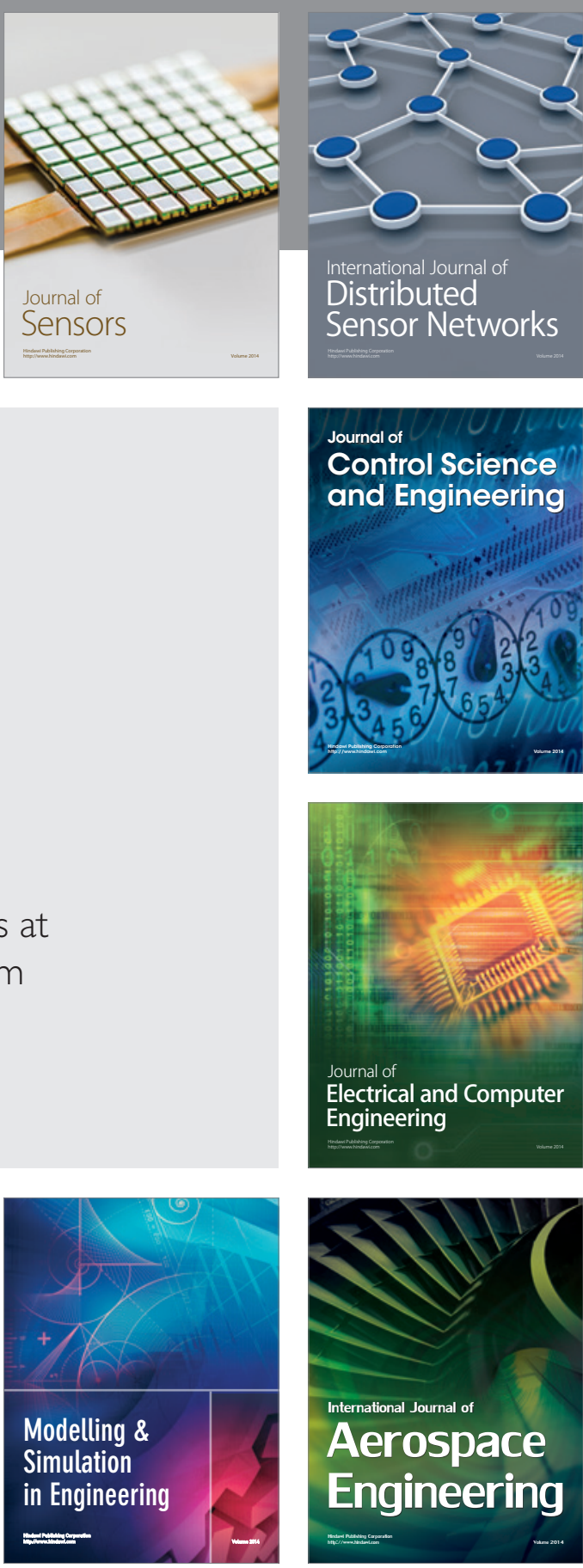

International Journal of

Distributed

Sensor Networks

Journal of

Control Science

and Engineering
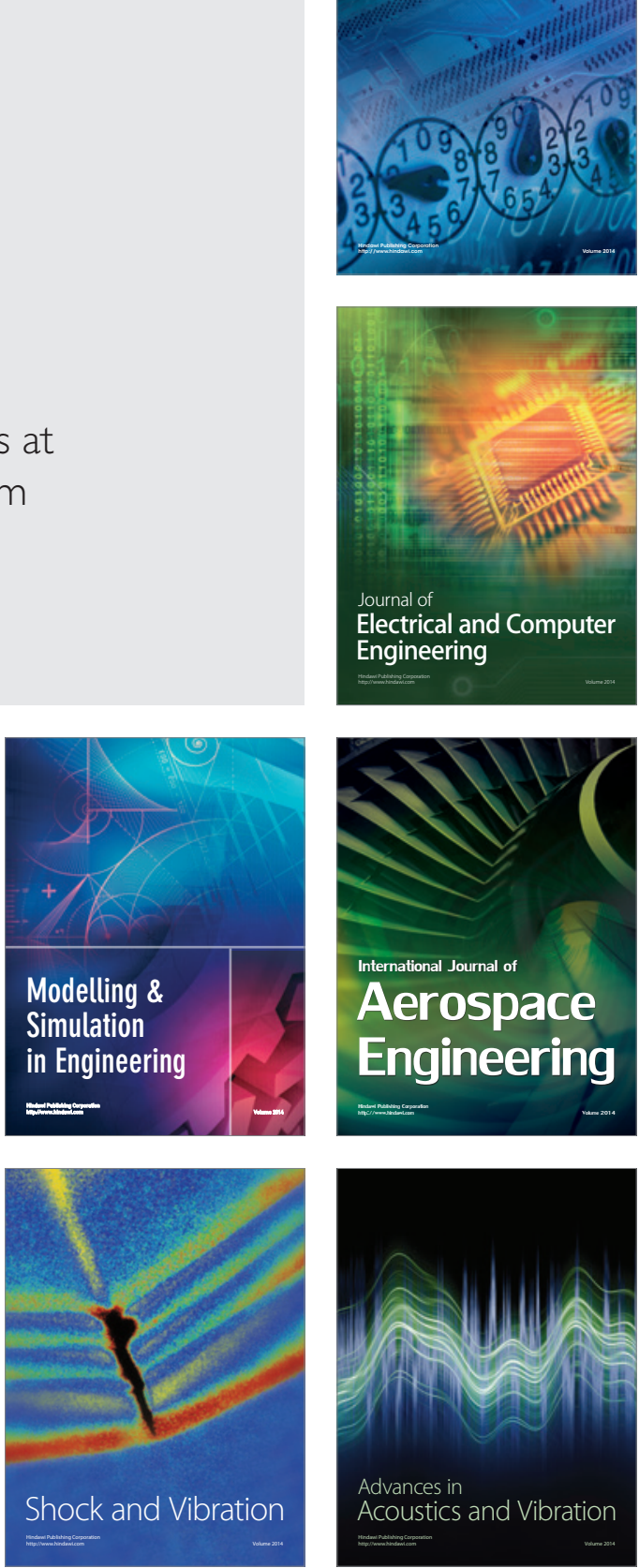